\title{
Observers Design and Implementation for DC Motor
}

\author{
Debabrata Pal \\ Aksum University, College of Engineering and Technology \\ Department of Electrical and Computer Engineering, Ethiopia, NE Africa
}

\begin{abstract}
This paper presents how to implement full-order and reduced-order observers using the software packages for computer aided control system design MATLAB. As a matter of fact, it has shown how to implement a dc motor state space model and its observer. Different observer gain(s) are determined by selecting different eigen values for the observers. Observer estimation errors are presented by choosing the observer(s) initial conditions. Having full understanding of the observer implementation(s), students and engineers will fill confident to use this observers and observer based controllers in numerous engineering and scientific applications.
\end{abstract}

Keywords: Observer Design, State space, DC Motor, Reduced-Order Observer, Implementation in MATLAB.

\section{Introduction}

Direct current machines are the most versatile energy conversion devices. Their outstanding advantage is that the volt-ampere or speed torque characteristic of these machines are very much flexible and easily adaptable for both steady state and dynamic operations. When a wide range of speed control and torque output are required dc motor is an obvious choice [1].

The state space approach is a generalized time domain method for modeling, analyzing and designing a wide range of control systems and is particularly well suited to digital computational technique. In this paper armature current and speed of the dc motor are taken as state variables.

Observers are used these days not only for the purpose of feedback control, but also in their own right to observe state variables of a dynamic system, which can be an experiment in progress whose state has to be monitored at all times. However, in the most recent editions of several standard undergraduate control system textbooks we can find the coverage of full-order and even reduced-order observers [2][4].

\section{DC Motor Modeling Using State Space Analysis}

The different equations related to DC motor are given below $e_{m}(\mathrm{t})=K_{m} \frac{d e[t]}{d t}$

$e_{a}(\mathrm{t})=L_{m} \frac{d i_{a}(t)}{d t}+R_{m} i_{a}(t)+e_{m}(t)$

$T(t)=K_{t} i_{a}(\mathrm{t})$

$\mathrm{J} \frac{d^{2}(t)}{d t^{2}}+\mathrm{B} \frac{d(t)}{d t}=T(t)$

Where $e_{a}(\mathrm{t})=$ armature voltage, $e_{m}(\mathrm{t})=$ back emf, $i_{a}(\mathrm{t})=$ armature current, $T(t)=$ developed torque, $\theta(t)=$ motor shaft angle, $\frac{d e(t)}{d t}=\omega(t)=$ shaft speed, $J=$ moment of inertia of the rotor, $\mathrm{B}=$ viscous frictional constant, $L_{m}=$ inductance of armature windings, $R_{m}=$ armature winding resistance, $K_{\mathrm{t}}=$ motor torque constant, $K_{\mathrm{m}}=$ motor constant.

Here the motor speed $\omega(\mathrm{t})$ is controlled by varying the armature voltage $e_{a}(\mathrm{t})$. Hence $e_{a}(\mathrm{t})$ is the input variable and $\omega(\mathrm{t})$ is the output variable.

We chose as the state variables $x_{1}(t)=\omega(t)=\frac{d e(t)}{d t}$

$$
\text { and } x_{2}(t)=i_{\alpha}(t)
$$

The state equations will now be derived by using above equations.

$$
\begin{gathered}
\frac{d x_{1}(t)}{d t}=-\frac{B}{I} x_{1}(t)+\frac{K_{t}}{I} x_{2}(t) \\
\frac{d x_{n}(t)}{d t}=-\frac{K_{m}}{L_{m}} x_{1}(t)-\frac{R_{m}}{L_{m}} x_{2}(t)+\frac{1}{L_{m}} e_{a} \\
y(t)=\frac{d e(t)}{d t}=\omega(t)=x_{1}(t)
\end{gathered}
$$

Hence state model of dc motor is derived from equations (6), (7) and (8) as follows

$$
\left[\begin{array}{l}
\frac{d x_{1}(t)}{d t} \\
\frac{d x_{2}(t)}{d t}
\end{array}\right]=\left[\begin{array}{cc}
-\frac{B}{J} & \frac{R_{t}}{J} \\
-\frac{K_{m}}{L_{m}} & -\frac{R_{m}}{L_{m}}
\end{array}\right]\left[\begin{array}{l}
x_{1}(t) \\
x_{2}(t)
\end{array}\right]+\left[\begin{array}{c}
0 \\
1 \\
L_{m}
\end{array}\right] \mathrm{u}
$$

(9)

$$
y(t)=\left[\begin{array}{ll}
1 & 0
\end{array}\right]\left[\begin{array}{l}
x_{1}(t) \\
x_{2}(t)
\end{array}\right]
$$




\section{International Journal of Science and Research (IJSR) \\ ISSN (Online): 2319-7064}

Index Copernicus Value (2013): 6.14 | Impact Factor (2014): 5.611

\section{DC Motor State Model Using Motor Parameters}

Let, the motor parameters (coefficient of differential equations) are assigned to be $\mathbb{I}_{\mathrm{m}}=0.5 \mathrm{H}, \mathbb{K}_{\mathrm{t}}=0.01 \mathrm{~N}-\mathrm{m} / \mathrm{A}$, $\mathbb{K}_{\mathrm{m}}=0.01 \mathrm{~V}-\mathrm{sec} / \mathrm{rad}, \mathrm{J}=0.01 \mathrm{~kg}-\mathrm{m} 2, \mathrm{~B}=0.1 \mathrm{~N}-\mathrm{m}-\mathrm{sec} / \mathrm{rad}$, $R_{\mathrm{m}}=1 \Omega$.

Thus the state model of dc motor is derived using motor parameters and equation (9) and (10) as follows:

$$
\begin{gathered}
{\left[\begin{array}{c}
\frac{d x_{1}(t)}{d t} \\
\frac{d x_{2}(t)}{d t}
\end{array}\right]=\left[\begin{array}{cc}
-10 & 1 \\
-0.02 & -2
\end{array}\right]\left[\begin{array}{l}
x_{1}(t) \\
x_{2}(t)
\end{array}\right]+\left[\begin{array}{l}
0 \\
2
\end{array}\right] \mathrm{u}(\mathrm{t})} \\
Y(t)=\left[\begin{array}{ll}
1 & 0
\end{array}\right]\left[\begin{array}{l}
\mathrm{x}_{1}(\mathrm{t}) \\
\mathrm{x}_{2}(\mathrm{t})
\end{array}\right]
\end{gathered}
$$

\section{Full Order Observer Design}

The theory of observers originated in the work of Luenberger in the middle of1960s, [9]-[11].According to Luenberger, any system driven by the output of the given system can serve as an observer for that system. Consider a linear dynamic system with unknown initial value of $x$

$$
\stackrel{x}{x}=A x+B u, y=C x
$$

A full order state observer estimates all of the system state variables. In practice this may not happen for a number of reasons including cost or that the state may not physically be measurable.

We define the mathematical model of the observer to be

$$
\ddot{\tilde{x}}=(\mathrm{A}-\mathrm{KeC}) \tilde{\boldsymbol{x}}+\mathrm{Bu}+\mathrm{Key}
$$

Where $\ddot{x}$ is the estimated state and $\mathrm{C} \ddot{x}$ is the estimated output. The $\mathrm{n} \times 1$ matrix $\mathrm{Ke}$ is called state observer gain matrix. Hence the observer error equation is defined by

$$
\begin{gathered}
\dot{x}-\ddot{\tilde{x}}=(\mathrm{A}-\mathrm{KeC})(x-\tilde{x}) \\
\dot{e}=(\mathrm{A}-\mathrm{KeC}) \mathrm{e}
\end{gathered}
$$

Where $(x-\tilde{x})=\mathrm{e}=$ observer estimation error vector. Thus the dynamic behavior of the error vector depends upon the Eigen values of $\mathrm{A}-\mathrm{KeC}$.

If the observer gain $\mathrm{Ke}$ is chosen such that the feedback matrix $\mathrm{A}-\mathrm{KeC}$ is asymptotically stable (has all eigen values with negative real parts) then the estimation error e will decay to zero for any initial condition of e. This stabilization requirement can be achieved if pair $(\mathrm{A}, \mathrm{C})$ is observable. The observer eigen values should be chosen to be about ten times faster than the system eigen values. This can be achieved by setting the smallest real part of the observer eigen values to be ten times bigger than the largest real part of the closed loop eigen values

$$
\left|\operatorname{Re}\left\{\lambda_{\min }\left(A-K_{a} C\right)\right\}\right|_{\text {absemagr }}>10\left|\operatorname{Re}\left\{\lambda_{\operatorname{mar}}(A-B R)\right\}\right|_{\text {gyatam }}
$$

Theoretically, an observer can be made arbitrarily fast by pushing its closed loop eigen values very far to the left in the complex plane, but very fast observers generate noise, and this is not desirable. In control system practice, instead of ten times, it is sufficient that the closed loop observer eigen values are faster than the closed loop system eigen values 5-6 times.

It is important to point out that the system observer configuration preserves the closed loop system eigen values that would have been obtained if the linear perfect state feedback control had been used. This fact will be shown in the follow up section. The system (14) under the perfect state feedback control, that is

$u=-K x$

has the closed loop form

$$
\bar{x}=(A-B K) x
$$

So the eigen values of the matrix $A-B K$ are the closed loop eigen values under perfect state feedback.

For state feedback control $\stackrel{*}{x}$, It is known that $u=-K x$

With this control, the state equation (13) becomes

$$
\begin{gathered}
\ddot{x}=A x-B K \tilde{x} \\
=(A-B K) x+B K(x-\ddot{x}) \\
=(A-B K) x+B K e
\end{gathered}
$$

Where $x-\check{x}=e=$ observer estimation error

Combining equations (18) and (15), we obtain

$$
\left[\begin{array}{l}
x \\
\dot{g}
\end{array}\right]=\left[\begin{array}{cc}
A-B K & B K \\
0 & A-K_{g} C
\end{array}\right]\left[\begin{array}{l}
x \\
e
\end{array}\right]
$$

The above equation describes the dynamic of the observed state feedback control.

Ackerman's formula is used to write the program in MATLAB command window. The programs are given below.

$>$ \% State feedback matrix $\mathrm{K}$ design using pole-placement technique

$$
\begin{aligned}
& \mathrm{A}=[-101 ;-0.02-2] \text {; } \\
& \mathrm{B}=[0 ; 2] ; \mathrm{C}=[10] ; \mathrm{D}=[0] \text {; } \\
& \mathrm{J}=[-2+\mathrm{j} * 1-2-\mathrm{j} * 1] \text {; } \\
& \mathrm{K}=\operatorname{acker}(\mathrm{A}, \mathrm{B}, \mathrm{J}) \\
& \mathrm{K}=32.4900 \quad-4.0000 \\
& >\text { \% State observer gain matrix Ke design }
\end{aligned}
$$

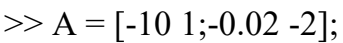

$$
\begin{aligned}
& \mathrm{B}=[0 ; 2] ; \mathrm{C}=[10] ; \mathrm{D}=[0] \text {; } \\
& \mathrm{L}=[-9 \text {-10]; } \\
& \mathrm{Ke}=\operatorname{acker}\left(\mathrm{A}^{\prime}, \mathrm{C}^{\prime}, \mathrm{L}\right)^{\prime} \\
& \mathrm{Ke}= \\
& 7.0000 \\
& 55.9800
\end{aligned}
$$




\section{International Journal of Science and Research (IJSR) \\ ISSN (Online): 2319-7064}

Index Copernicus Value (2013): 6.14 | Impact Factor (2014): 5.611

\section{Reduced Order Observer Design}

A reduced-order state observer estimates fewer than $n$ state variables where $\mathrm{n}$ is the dimension of the state vector.

Consider equation (13) where the state vector $x$ can be partitioned into two parts $x_{0}$ (a scalar) and $x_{b}$ (a vector). Here the state variable $x_{a}$ is equal to the output $y$ and thus can be directly measured and $x_{b}$ is the unmeasurable portion of the state vector. Then partitioned state and output equations become

$$
\begin{gathered}
{\left[\begin{array}{l}
x_{a}^{a} \\
x_{b}^{a}
\end{array}\right]=\left[\begin{array}{ll}
A_{a a} & A_{a b} \\
A_{b a} & A_{b b}
\end{array}\right]\left[\begin{array}{l}
x_{a} \\
x_{b}
\end{array}\right]+\left[\begin{array}{l}
B_{a} \\
B_{b}
\end{array}\right] \mathrm{u}} \\
\mathrm{y}=\left[\begin{array}{ll}
1 & 0
\end{array}\right]\left[\begin{array}{l}
x_{a} \\
x_{b}
\end{array}\right]
\end{gathered}
$$

From equation (20) the equation for the measured portion and unmeasured portion of the state becomes.

$$
\begin{aligned}
& x_{a}^{n}=A_{a a} x_{a}+A_{a b} x_{b}+B_{a} \mathrm{u} \\
& x_{b}^{n}=A_{b a} x_{a}+A_{b b} x_{b}+B_{b} \mathrm{u}
\end{aligned}
$$

Here equation (23) and (22) are known as ,state equation and ,output equation ${ }^{\text {ee }}$ for the minimum order observer.

The equation for the full order observer is

$$
\ddot{\tilde{x}}=(\mathrm{A}-\mathrm{KeC}) \tilde{\tilde{x}}+\mathrm{Bu}+\mathrm{Key}
$$

Then making the substitution of table 1 into last equation we obtain

\begin{tabular}{|c|c|}
\hline Full order state observer & $\begin{array}{c}\text { Minimum order state } \\
\text { observer }\end{array}$ \\
\hline$\hat{\bar{x}}$ & $\widehat{x_{\tilde{b}}}$ \\
\hline A & $A_{b b}$ \\
\hline $\mathrm{Bu}$ & $A_{b a} x_{a}+B_{b u}$ \\
\hline $\mathrm{y}$ & $x_{a}^{n}-A_{a a^{-}} x_{a}-B_{a} \mathrm{u}$ \\
\hline $\mathrm{C}$ & $A_{a b}$ \\
\hline $\mathbb{K}_{g}(\mathrm{n} \times 1$ matrix $)$ & $k_{g}[(n-1) \times 1$ matrix $]$ \\
\hline
\end{tabular}

$$
\overrightarrow{x_{b}}=\left(A_{b b}-\mathbb{k}_{a} A_{a b}\right) \widetilde{x_{b}}+A_{b a} x_{a}+B_{b} \mathrm{u}+\mathbb{k}_{a} A_{a b} x_{b}
$$

Table 1: List of necessary substitutions for writing the observer equation for the minimum order state observer

By subtracting equation (20) from equation (18) we obtain $x_{b}^{x}-\vec{x}_{b}=\left(A_{b b}-k_{a} A_{a b}\right)\left(x_{b}-\widetilde{x}_{b}\right)$

Define $\mathrm{e}=x_{\tilde{b}}-\widetilde{x_{\mathfrak{b}}}$

Then equation (21) becomes

$\stackrel{g}{e}=\left(A_{b b}-\mathbb{K}_{g} A_{a b}\right) \mathrm{e}$
This is the error equation for the minimum order observer. The dynamic behavior of error vector depends upon the Eigen values of $A_{b b}-k_{a} A_{a b}$.

Now the characteristic equation for the minimum order observer is obtained the equation as follows.

$\left\|S I-A_{b b}+k_{g} A_{a b}\right\|=\left(\mathrm{s}-m_{1}\right)\left(\mathrm{s}-m_{2}\right) \ldots\left(\mathrm{s}-m_{\mathrm{g}-1}\right)=0$

Where $m_{1}, m_{2 x} \ldots \ldots \ldots \ldots m_{n-1}$ are desired Eigen values for the minimum order observer. Suppose the desired location of the Eigen value for the minimum observer is at $\mathrm{s}=-9$.

The minimum observer gain matrix is designed by the following MATLAB program.

Ackerman's formula is used to write the program in command window. The program is given below.

$>\%$ State observer gain matrix Ke design.

$>\mathrm{Aab}=[1] ; \mathrm{Abb}=[-2]$

$>\mathrm{LL}=[-9]$

$>\mathrm{Ke}=\operatorname{acker}\left(\mathrm{Abb}^{\prime}, \mathrm{Aab}, \mathrm{LL}\right)^{\prime}$

$\mathrm{Ke}=7$

The system dynamics for reduced-order observer is defined by the given equation.

$$
\left[\begin{array}{l}
x \\
e
\end{array}\right]=\left[\begin{array}{cc}
A-B K & B k_{b} \\
0 & A_{b b}-k_{g} A_{a b}
\end{array}\right]\left[\begin{array}{l}
x \\
e
\end{array}\right]
$$

\section{Observation Error Comparison}

The obtained differences between the actual state trajectories and estimated state trajectories using the full and reducedorder observers for dc motor are presented in Figures 1 and 2 . In both cases the initial conditions are taken as ; $\mathrm{x} 1(0)=1$, $\mathrm{x} 2(0)=0, \mathrm{e} 1(0)=1, \mathrm{e} 2(0)=0, \mathrm{e}(0)=1$.
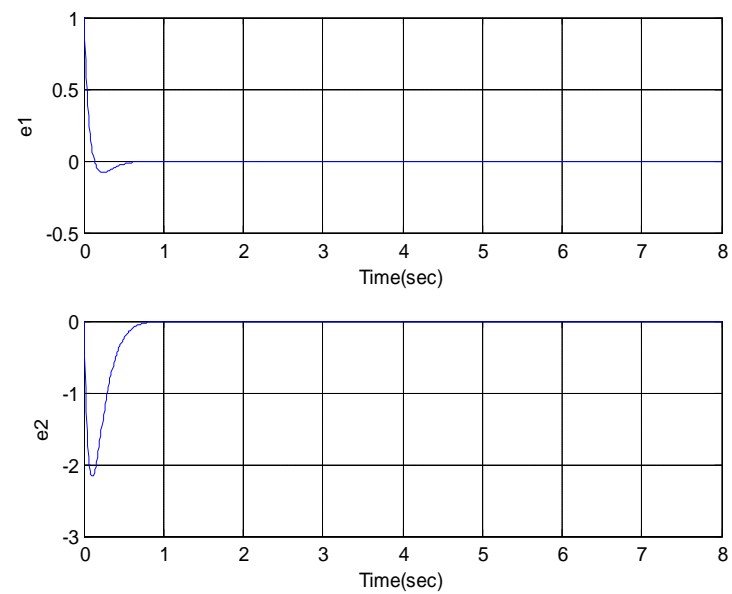

Figure 1: Full-order observation estimation error 


\section{International Journal of Science and Research (IJSR) \\ ISSN (Online): 2319-7064}

Index Copernicus Value (2013): 6.14 | Impact Factor (2014): 5.611

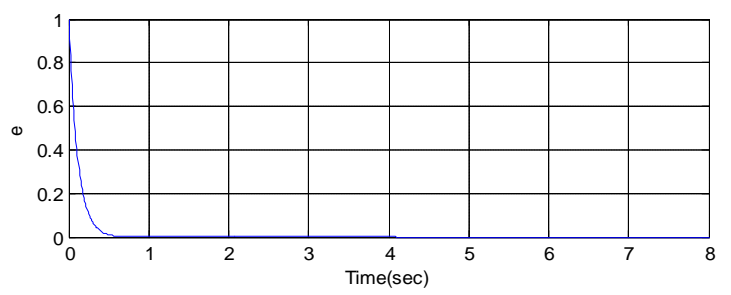

Figure 2: Reduced -order observation estimation error

It can be seen from Figures 1 and 2 that the reduced-order observer is superior over the full-order observer because the reduced-order observer is more accurate than the corresponding ones observed by the full-order observer. Note that the eigen values for both observers are placed to be of the same speed. The reduced- order observer value is placed at -9 and the full-order observer values are placed at $-9,-10$. Even more, the reduced-order is simpler for implementation since they are dynamical systems of lower order that the original systems.

\section{Conclusion}

It has shown in detail how to implement full-order and reduced-order observers in MATLAB environment and presented corresponding fundamental derivation and results with the help of dc motor state model. I hope this paper will motivate undergraduate and graduate students to further study observers and use them as powerful tools for observing system dynamics and/or designing feedback control loops.

\section{References}

[1] Dr. P.S. Bimbhra, ,Electrical Machines ${ }^{e e}$ KHANNA PUBLSHER

[2] Katsuhiko Ogata, „Modern Control Engineeringe, PEARSON PUBLISHER.

[3] Charles L. Philips \& Royce D. Harbor, „Feedback Control Systems ${ }^{e}$, PRENTICE HALL PUBLISHER

[4] Roland S. Burns „Advanced Control Engineeringe, BUTTERWORTH HEINENANN, A Division of reed educational and professional publishing limited.

[5] Devendra K. Chaturvedi, Modeling and simulation of system using MATLAB and Simulink, CRC Press Taylor and Francis group Boca Raton London New York 2010.

[6] M. S. RUSU, and L. Grama, The Design of a DC Motor Speed Controller, Fascicle of Management and Tech. Eng., Vol. VII (XVII), 2008, pp. 1055-1060.

[7] Debabrata Pal, "Modeling, analysis and design of a dc motor based on state space approach" IJERT, volume 5 Issue 2, February 2016, pp293-296.

[8] Debabrata Pal, "Full order observer controller design for dc motor based on state space approach", International Journal of science and research (IJSR), volume 5 Issue 2, February 2016, pp1752-1756.

[9] D. Luenberger,'Observing the state of a linear system," IEEE Transactions on Military Electronics, Vol. 8, 7480, 1964. [10] D.Luenberger,"Observers for multivariable
systems,"IEEE Transactions on Automatic Control, Vol.AC-11,190-197, 1966.
[11]D. Luenberger, "An introduction to observers," IEEE Transactions on Automatic Control, Vol.AC-16,596602, 1971.

[12]C.D Johnson, "Optimal initial condition for full order observers,'International journal of Control, Vol.48, 857864, 1988.

\section{Author Profile}

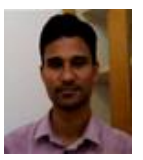

Debabrata Pal was born in Bankura, West Bengal, India. He has received his B.Tech degree in Electrical Engineering in 2005 from West Bengal University of Technology, India and Master's degree in Electrical Systems in 2010 from National Institute of Technology, Durgapur, India. His research interest is in Renewable Energy Sources, Control Engineering and Machine Simulation.

He has been teaching in various universities in India for more than eight years in various capacities (2005-2013). He is currently Assistant Professor in the Department of Electrical and Computer Engineering, College of Engineering and Technology, Aksum University, Aksum, Ethiopia from 2013 to present. 